\title{
Erratum to: Spillover effects of maternal education on child's health and health behavior
}

\author{
Daniel Kemptner · Jan Marcus
}

Published online: 2 February 2013

(C) Springer Science+Business Media New York 2013

\section{Erratum to: Rev Econ Household \\ DOI 10.1007/s11150-012-9161-x}

Unfortunately, the upper part of Table 6 has been repeated in table's lower part erroneously in the original publication.

The corrected version of Table 6 is shown here.

The online version of the original article can be found under doi:10.1007/s11150-012-9161-x.

D. Kemptner $(\bowtie) \cdot$ J. Marcus

DIW Berlin, Mohrenstraße 58, 10117 Berlin, Germany

e-mail: dkemptner@diw.de

J. Marcus

e-mail: jmarcus@diw.de 


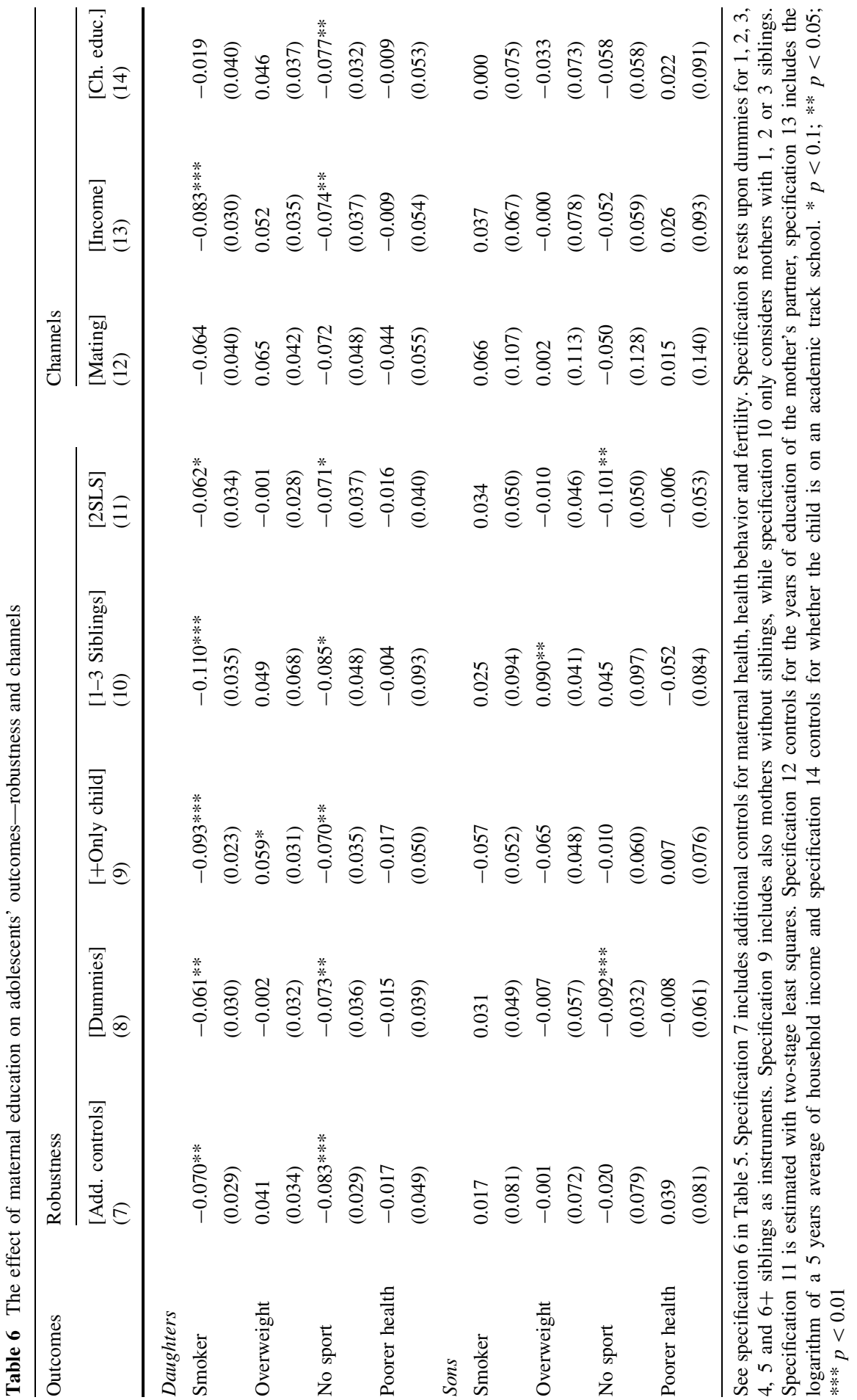

